\title{
The partial labyrinthectomy petrous apicectomy approach to petroclival menin- giomas. A quantitative anatomic comparison with other approaches to the same region
}

\author{
C. Mandelli; L. Porras*; C. López-Sánchez**; G.M. Sicuri; I. Lomonaco and V. García-Martínez**
}

Department of Neurosurgery. IRCCS San Raffaele. Università Vita-Salute. Milano. Italy. Department of Neurosurgery*. Infanta Cristina Hospital. Badajoz. Spain. Department of and Anatomy**. Universidad de Extremadura. Badajoz. Spain,

\section{Summary}

The partial labyrinthectomy petrous apicectomy (PLPA) approach is a transpetrous route that provides the advantages of the labyrinthine removal but with hearing preservation. Using seven temporal bone tissue blocks and three formaldehyde-fixed cadaveric heads we have made a morphometric and comparative study on this approach that summarizes the invasiveness, the optimal surgical exposure, the anatomic complexity of the skull base approaches and, on the other hand, the spirit of preservation that is the constant aim of modern neurosurgery. The morphometric analysis is designed to make the bony phase of the PLPA approach safer and to define the relationship between petrous landmarks. The comparative study is made between the PLPA and other neurosurgical routes enhancing the potentiality of the PLPA approach that permits a wider angle of incidence towards the brainstem than with the retrosigmoid routes.

KEY WORDS: Meningioma. Partial labyrinthectomy. Petroclival. Petrosal approach. Rretrosigmoid approach.

La laberintectomia parcial con apicectomía petrosa como acceso a los meningiomas petroclivales. Una comparación anatómico - quantitativa con otras vías de abordaje a la misma zona

\section{Resumen}

La laberintectomía parcial con apicectomía petrosa (PLPA) es una vía de abordaje que proporciona las ventajas de la extirpación parcial del laberinto preservando la audición. Trabajando sobre 7 piezas anatómicas de hueso temporal y 3 cabezas de cadáver fijadas con formaldehido, hemos realizado un estudio morfométrico y comparativo de este abordaje interesándonos los aspectos de la invasividad del abordaje, óptima expo-

Recibido: 2-05-07. Aceptado: 6-06-.07 sición quirúrgica obtenida, complejidad anatómica de la entrada a la base craneal, y por otra parte, la actitud conservadora de la moderna neurocirugía. El análisis morfométrico tiene como objetivo hacer la fase ósea de la PLPA más segura al definir la relación entre los puntos de referencia petrosos. El estudio comparativo entre la PLPA y otros abordajes neuroquirúrgicos exalta la posibilidades de la PLPA ya que proporciona un ángulo de incidencia hacia el tronco cerebral máos amplio que el que proporcionan las vías retrosigmoideas.

PALABRAS CLAVE: Meningioma. Laberintectomía parcial. Petroclival. Abordaje petroso. Abordaje retrosigmideo.

\section{Introduction}

The partial labyrinthectomy petrous apicectomy approach (PLPA) or transcrusal approach ${ }^{6}$ is a relatively new surgical route to the petroclival region ${ }^{4,6,16,17}$.

It has the advantages of exposure linked to the transpetrosal corridor but with minimal post-operative morbidity resulting from manipulation of the anatomic structures in the way. This approach provides a transpetrous corridor for removing the mastoid, the superior and posterior semicircular canals and the petrous apex but without hearing loss.

This morphometric anatomic study on the PLPA bony phase was designed to collect and relate the surgical landmarks useful to the surgeon during this difficult phase. We also wanted to make quantitative measurements on the osteo-dural and nervous surfaces for this approach, comparing them with others obtained by currently popular surgical routes in order to evaluate the different degrees of each surgical exposure. The other approaches considered

Abreviations. EAC: external auditory canal. ETCA: enlarged transcochlear approach. FN: facial nerve. ICA: internal carotid artery. PLPA: partial labyrinthectomy petrous apicectomy. RISTA: retrosigmoid intradural suprameatal transpetrous apex. $R S$ : retrosigmoid. SD: standard deviation. SS: sigmoid sinus. 


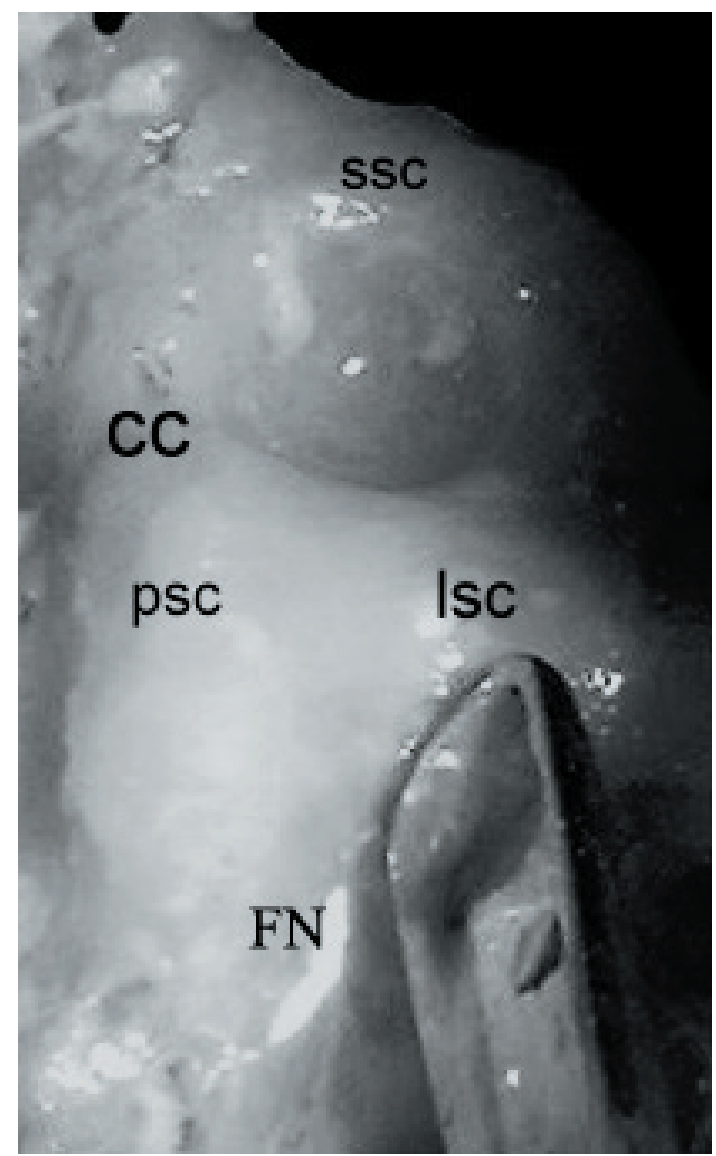

ssc: superior semicircular canals. lsc: lateral semicircular canals. psc: posterior semicircular canals. CC: common crus. FN: facial nerve.

Figure 1. The superior, lateral and posterior semicircular canals with the common crus are skeletonised. The dissector shows the relationship between the lsc and the third segment of the facial nerve. The covering bony shell has been partially removed to point out the FN. (right site).

are the sub-occipital retrosigmoid approach (RS), the retrosigmoid intradural suprameatal transpetrous apex approach (RISTA) and the combined enlarged transcochlear approach (ETCA).

The least invasive approach is the $\mathrm{RS}^{11,18}$; this is the classic neurosurgical route to the cerebello-pontine angle which implies a retrosigmoid craniectomy and its surgical light is along the posterior petrous surface. The RISTA is an extension of the RS approach, through an intradural apicectomy ${ }^{12,19}$.

Finally, the ETCA, executed according to the cadaveric studies of Sanna et al. ${ }^{14}$, is one of the most invasive skull base approaches in which the surgical corridor is through the petrous bone after complete mastoidectomy, with posterior transposition of the third segment of the facial nerve (FN) and radical removal of the otic capsule and apicec-

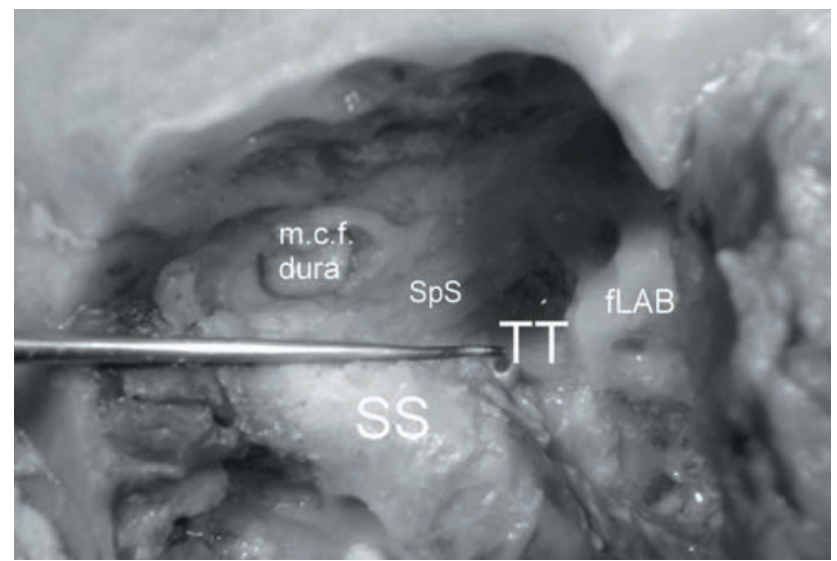

SpS: superior petrosal sinus. fLAB: fenestrated labyrinth. SS: sigmoid sinus. TT: Trautmann's triangle. m.c.f. dura: medial cranial fossa dura.

Figure 2. The area of the posterior fossa dura enclosed between the superior petrosal sinus, the jugular bulb, the labyrinth and the sigmoid sinus is represented. It corresponds to the Trautmann's triangle.

tomy.

\section{Materials and methods}

Seven tissue blocks (four right and three left) were removed from cadavers with no history of disease involving the central nervous system or skull base. There were five males and two females, aged 57 to 79 years [mean 63.3 years; standard deviation (SD) 7.5 years]. Each specimen included the temporal bone, sella turcica, part of the clivus, homolateral sigmoid sinus (SS), homolateral transverse sinus, dura mater covering the endocranial surface of the skull base, the muscles of the infratemporal fossa inserted on the lateral cranial base, and the ascending branch of the mandible. The internal carotid artery (ICA) and the jugular vein were washed with hot tap water then injected with colored silicone (red for the artery and blue for the vein). Each specimen was preserved in $66 \%$ ethanol solution for 24 hours before being dissected ${ }^{13}$. The tissue blocks were placed in the surgical position used for the PLPA. The dissection and measurements were made under magnification using the operative microscope (Leica MS®, Switzerland).

The mastoid was drilled until all three semicircular canals and the vertical segment of the FN were exposed (Fig 1). Identification of the superficial anatomic landmarks was the key point for the first phase of the procedure ${ }^{10,14,16,17}$.

The following landmarks were considered: the floor of the middle cranial fossa, the tip of the mastoid, Macewen's triangle (suprameatal triangle) and Henle's spine, the external auditory canal (EAC), the sinodural angle (SDA: the 


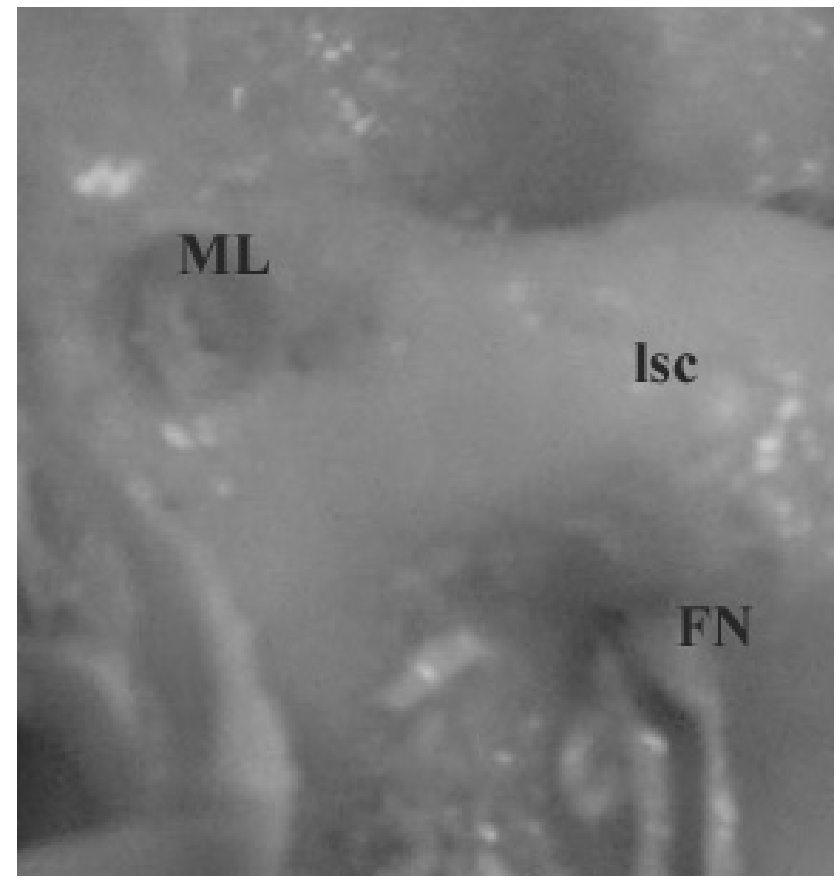

ML: membranous labyrinth. lsc: lateral semicircular canals. FN: facial nerve.

Figure 3. View of the membranous labyrinth obtained after fenestration of the ampullated ends of the common crus. The relationship between the third segment of the VII c.n. and the lateral semicircular canal is a key point for the surgical exposition of this nerve.

dural space between the superior petrosal and sigmoid sinuses and the middle fossa dura), and the aditus ad antrum.

Exposure of the FN required identification of the lateral semicircular canal $(l s c)$ and of the digastric ridge; to skeletonize the middle cranial fossa dura and the dural section inside Trautmann's triangle [i.e. the area of posterior fossa dura mater exposed through the mastoid cavity between the superior petrosal sinus (SpS), the jugular bulb (JB), the endolymphatic sac and the otic capsule ${ }^{10}$ (Fig.2)] requires identification of each of these deeper anatomic structures.

Removing any semicircular canal with preservation of hearing means that the membranous canal must not be violated $^{7}$.

For this reason a small $(2 \times 3 \mathrm{~mm})$ fenestration of the ampullated ends of both posterior ( $p s c)$ and superior ( ${ }^{\mathrm{ssc}}$ ) semicircular canals and also of the common crus was obtained $^{16,17}$ (Fig. 3). Once opened, the canals were occluded with bone wax in order to drill away the bony and membranous labyrinth of the psc and ssc without losing endolymphatic fluid. The petrous apicectomy was finally performed, facilitated by partial removal of the labyrinth. The bone was drilled superior to Donaldson's line drawn between the ampulla of the ssc and the entrance of the vestibular aqueduct into the petrous dura ${ }^{16,17}$ (Fig. 4 A-B). Linear measurements were made with a microcaliper and angles were measured using a goniometer, in each phase of the osseous procedure.

The second part of the study involved bilateral stepwise dissections on three formalin-fixed cadaveric heads (five sides - two right and three left) under magnification (Zeiss MS ${ }^{\circledR}$, Switzerland). The following surgical approaches were taken, starting with the least invasive one: RS, RISTA, PLPA, ETCA.

To begin the procedure, the head was turned away from the side of the RS approach to simulate the semiprone surgical position. The usual retrosigmoid $4-5 \times 4 \mathrm{~cm}$ craniectomy was done. After opening the dura we made a $1-\mathrm{cm}$ wedge resection of the cerebellar lobe to simulate its retraction because of the hardening of the formaldehydefixed brain. The measurements were based on this parameter as a constant.

RISTA was the second procedure. The dura mater over the suprameatal tubercle was incised and the bone was drilled at this level (Fig. 5), avoiding the posterior part of the ssc, the superior part of the psc and the common crus. Apicectomy was then done, removing the petrous bone below Meckel's cave to the edge of the petroclival fissure laterally to the VI cranial nerve (c.n.). The dissection was then extended to permit the PLPA. The petrous bony phase was carried out as previously described, considering the apicectomy as the extradural completion of the RISTA. The retrosigmoid dura was always assumed to be closed and skeletonized.

The cutaneous incision was continued upward, drawing a " $\mathrm{C}$ " around the auricular region, to give a temporal craniotomy. The combination of both cranial openings summarizes the advantages of the supra- and infratentorial exposure for this approach. A $1.5-\mathrm{cm}$ wedge resection of the inferior gyros of the temporal lobe was done to simulate its retraction, after opening the dura along the base of the temporal craniotomy, examining the course of the vein of Labbé. The dural incision was continued parallel to and just behind the petrous ridge after division of the SpS, and then extended towards the tentorial edge avoiding the IV c.n. The dural opening was then extended inside Trautmann's triangle, $2 \mathrm{~mm}$ anteriorly to the SS that was appropriately unroofed.

The ETCA was the last and most invasive approach. It included transection of the EAC at its bony cartilaginous junction. The petrosectomy was initially extended by removing the tympanic membrane and ossicles. After removing the bony EAC we performed a labyrinthectomy, exposing the IAC in $270^{\circ}$ of its circumference. The FN was freed from its bony canal after exposure of the geniculate ganglion and section of the greater petrosal nerve. The VII c.n. was followed at the fundus of the IAC and posteriorly 

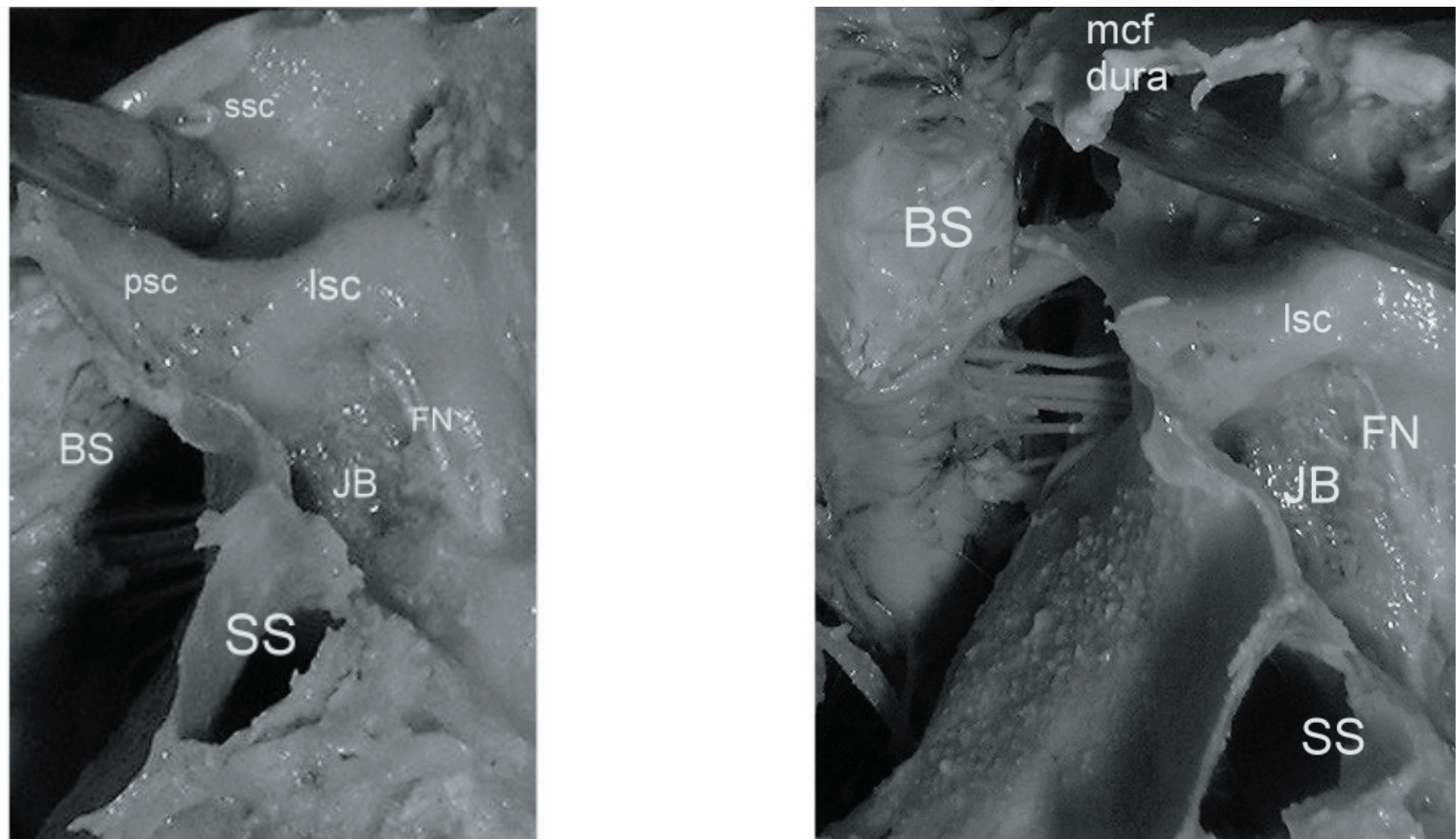

ssc: superior semicircular canals. lsc: lateral semicircular canals. psc: posterior semicircular canals. FN: facial nerve. BS: brainstem. JB: jugular bulb. SS: sigmoid sinus.m.c.f. dura: medial cranial fossa dura.

Figure 4. (A) The cerebellar lobe has been partially removed to show the brachium pontis. It is visible the interposition of the labyrinth between the surgeon and the brainstem. The sigmoid sinus has been dissected and sectioned. (B) Surgical corridor after removal of the posterior and superior semicircular canals during PLPA. The cerebellar lobe and the posterior cranial fossa dura are removed. The sigmoid sinus has been dissected.

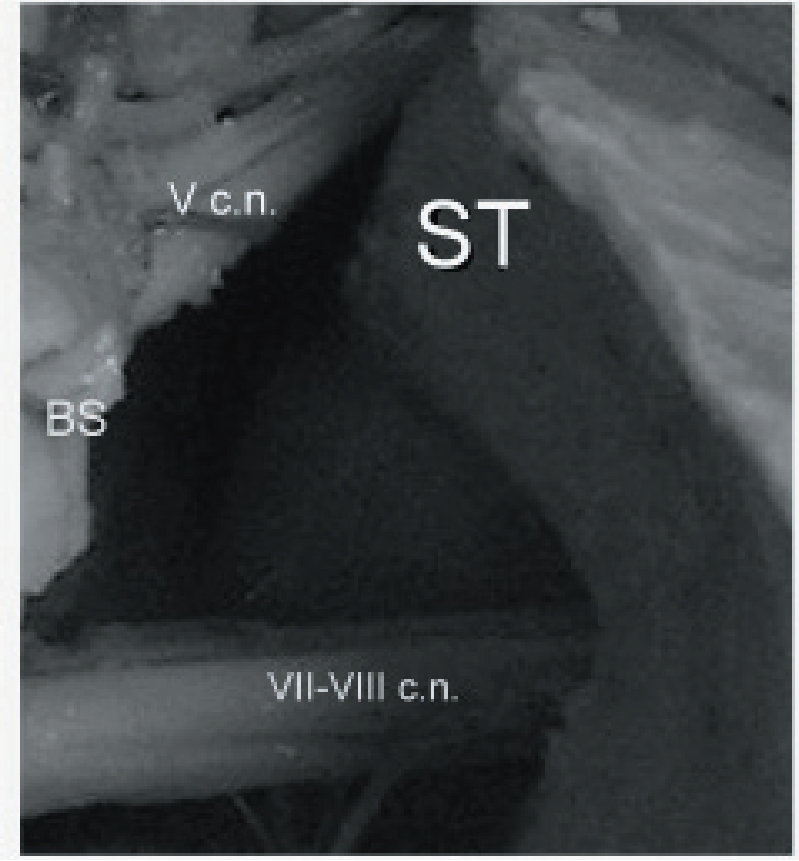

BS: brainstem. ST: suprameatal tubercle. c.n.: cranial nerve. Figure 5. The quadrangular area located between the brainstem, the petrous posterior surface, the V c.n. and the statoacoustic bundle is represented. The drill should be inserted into this area to remove the suprameatal tubercle during RISTA transposed. The apicectomy was completed medially to the vertical segment of the ICA, exposing the petro-occipital synchondrosis, the inferior petrosal sinus and the JB. The dural opening was started over the mid-portion of the IAC and extended superiorly and inferiorly around the porus acusticus. It was then extended antero-superiorly towards the cavernous sinus and then towards the junction of the inferior petrosal sinus with the JB. From this point it was continued posteriorly towards the SS. Another dural incision was drawn from the IAC to the SpS (below this one) and the pre-sigmoid, temporal and tentorial dural incisions obtained for the PLPA were used. The retrosigmoid dura was always assumed to be closed and skeletonized.

Step-by-step linear, angular and surface measurements on the petroclival area and brainstem were obtained for each approach. We used a long microcaliper and a goniometer. The clival length and the percentage of clival exposure through each approach were obtained by dipping the end of the dissector in dye. We used the clival subdivision into Zones I,II, and III, as suggested by Aziz et al.' (Fig. 6). Each approach was characterized by a specific color and the two extremities of maximal clival length exposure for each surgical route were marked using the colored dissector. At the end of the entire dissection, the brain was removed and the length and percentage of clival exposure were 


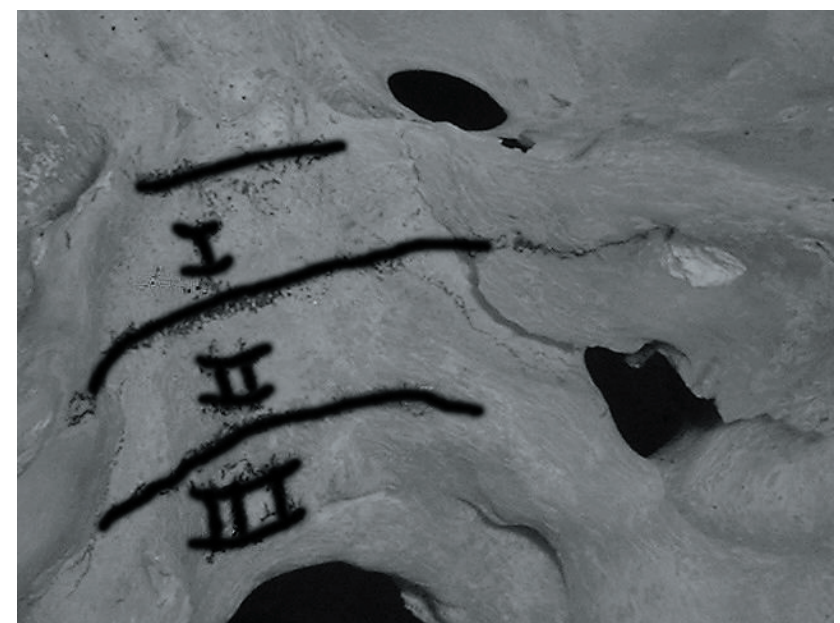

Figure 6. The clival subdivision into Zones I, II, and III as suggested by Aziz et al.

measured and calculated using the same colored markers.

\section{Results}

The results are summarized in Tables 1 and 2 (A-B). During the transpetrous procedures preservation of the membranous labyrinth is mandatory to avoid massive perilymph-endolymph contamination and consequent hearing $\operatorname{loss}^{7}$. Our morphometric measurements are intended to make the bony phase of the PLPA safer and to facilitate preservation of the membranous labyrinth (Table 1).

Visualization of the SDA and basitemporal dura is one of the key points in the first phase of mastoidectomy (the SDA is $22.6 \mathrm{~mm}$ from the posterior root of the zygoma) and we suggest maintaining the calvarial border at the passage point between the temporal and basitemporal dura as a visual reference to calculate the depth of drilling from our key points: Henle's spine and cortical surface of the mastoid triangle at the junction of the triangle's median.

The mastoid and suprameatal triangles are the correct surfaces for starting drilling; first blue-outline the $l s c$ at about $17.6 \mathrm{~mm}$ from the cortical surface at the suprameatal triangle (avoiding the VII c.n. which is less than $1 \mathrm{~mm}$ from this semicircular canal) (Fig. 3) and then the psc which is $3.6 \mathrm{~mm}$ from the VII c.n., almost perpendicular to the $l s c$, and $7.8 \mathrm{~mm}$ from the SS curvature. This canal is close to the endolymphatic sac that must be preserved to maintain the patient's hearing ${ }^{14}$. Identifying the ssc along the SDA is the next step of the procedure. The canal is $27.6 \mathrm{~mm}$ deep from the mastoid cortex at the level of the SDA and is just below the superior petrous surface at the level of the arcuate eminence; it describes a $89.8^{\circ}$ angle with the petrous ridge. We suggest maintaining progressive skeletonization of the basitemporal dura while drilling towards the ssc because it is a structure that provides contrast with the bone both in consistency and in color. The otic capsule has a bright ivory bone, the mastoid offers spongy bone and the dura mater has an elastic texture. These phases of the labyrinthine skeletonization should also consider the distance from the JB and its shape (rounded in $80 \%$ of specimens), especially during the exposure of the $p s c$ and the endolymphatic sac.

This bony phase and the successive ones are safer in petrous bones with "large" mastoids $[\geq 35 \mathrm{~mm}$ long, according to Aslan et al. ${ }^{3}$ ] because it is possible to obtain a wider surgical corridor and a better working burr hole angle. This consideration also holds for Trautmann's triangle. In one of our tissue blocks this area measured about $100 \mathrm{~mm}^{2}$, making it difficult to expose the endolymphatic sac and the psc aspect towards the posterior cranial fossa dura.

The labyrinthine area drilled away during PLPA is triangular with a low but critical mean value of $24.5 \mathrm{~mm}^{2}$ (its tips are the fenestrations on the ampullated ends of the $p s c$ and ssc and on the common crus).

After partial labyrinthectomy and apicectomy, the transcrusal approach involves a surgical corridor that is just perpendicular to the clival border and begins narrowing at the level of the ssc and psc, that have been removed. This kind of angulation contributes to the degree of exposure of the osteodural surfaces during the PLPA.

The quantitative analysis and the comparison with the other surgical routes is centered on three key measurements for each approach (Table 2A):

1. Exposure of the $\mathrm{V}$ c.n. helps evaluate the progression toward Meckel's cave for each approach.

2. Exposure of the clivus (absolute value and percentage for each Aziz's zone) permits an evaluation of the extension of the approaches in the sagittal plane.

3. Exposure of the brainstem surface (section reached non-tangentially) is useful to evaluate the angle of incidence toward the brainstem. A higher incidence corresponds to a larger area of brainstem controlled during tumor removal.

The V c.n. exposure is from $8 \mathrm{~mm}$ for the classic RS to $15 \mathrm{~mm}$ for the ETCA. The RISTA, with its mean value of $12 \mathrm{~mm}$, provides good control of Meckel's cave even if it is a retrosigmoid procedure. The PLPA produces a mean of $13.5 \mathrm{~mm}$ that is close to that of the ETCA. We have a similar situation for the clivus exposure. The PLPA mean value is $28.5 \mathrm{~mm}$ and ETCA gives $30 \mathrm{~mm}$. The latter allows better control of the Zone III than the other approaches. The RISTA produces a $24.8 \mathrm{~mm}$ exposure but, according to Aziz's zones, it especially covers the upper and middle clivus.

The working area (quadrangular area) in which the burr should be positioned during this approach has the following borders: brainstem, petrous posterior surface, $\mathrm{V}$ 
Table 1

Morphometric analysis: anatomic morphometric measurements of the PLPA bony phase subdivided according to each key landmark

\begin{tabular}{|c|c|c|c|}
\hline ANATOMIC LANDMARKS & MEAN & SD & RANGE \\
\hline $\begin{array}{l}\text { 1) Mastoid } \\
\text { - mastoid length (from the m.c.f. to the tip) } \\
\text { - classification of the mastoid length: } \\
\qquad \begin{array}{l}\text { large }>35 \mathrm{~mm}(\%) \\
\text { small }<35 \mathrm{~mm}(\%)\end{array}\end{array}$ & $\begin{array}{l}32 \mathrm{~mm} \\
60 \% \\
40 \%\end{array}$ & $\begin{array}{c}6,5 \mathrm{~mm} \\
- \\
-\end{array}$ & $\begin{array}{l}25-39 \mathrm{~mm} \\
- \\
-\end{array}$ \\
\hline $\begin{array}{l}\text { 2) SDA } \\
\text { - SDA vs posterior root of the zygoma } \\
\text { - SDA vs ssc (at the level of the cortical mastoid surface) }\end{array}$ & $\begin{array}{l}22,6 \mathrm{~mm} \\
27,6 \mathrm{~mm}\end{array}$ & $\begin{array}{l}3,1 \mathrm{~mm} \\
1,8 \mathrm{~mm}\end{array}$ & $\begin{array}{l}20-25 \mathrm{~mm} \\
26-30 \mathrm{~mm}\end{array}$ \\
\hline $\begin{array}{l}\text { 3) Semicircular canals: } \\
\text { Linear measurements } \\
\text { - lsc depth (tip of the curvature) from the cortical surface } \\
\text { of the suprameatal triangle } \\
\text { - psc depth (tip of the curvature) from the cortical } \\
\text { surface of the mastoid triangle (junction of the } \\
\text { triangle's mediana) } \\
\text { - ssc depth (tip of the curvature) from the cortical } \\
\text { surface of the mastoid triangle (junction of the } \\
\text { triangle's mediana) } \\
\text { 1. Angular measurements } \\
\text { - psc vs lsc } \\
\text { - sc vs petrous ridge } \\
\text { 2.Area measurements } \\
\text { - area occupied by the ssc and psc removed after PLPA. } \\
\text { It is a triangular area and its sides are: } \\
\text { A. the line between the fenestrated psc ampulla and } \\
\text { the common crus } \\
\text { B. the line between the fenestrated ssc ampulla and } \\
\text { the common crus } \\
\text { C. the line between the ampullar fenestrations on the } \\
\text { psc and ssc } \\
\text { - area of p.c.f. dura exposed before the partial } \\
\text { labyrinthectomy (Trautmann's triangle) }\end{array}$ & $\begin{array}{l}88^{\circ} \\
89,8^{\circ} \\
24,5 \mathrm{~mm}^{2}\end{array}$ & $\begin{array}{l}4,5^{\circ} \\
5,3^{\circ} \\
3,9 \mathrm{~mm}^{2}\end{array}$ & $\begin{array}{l}80-91^{\circ} \\
84-95^{\circ} \\
18-27,5 \mathrm{~mm}^{2}\end{array}$ \\
\hline $\begin{array}{l}\text { 4) } 3^{\circ} \mathrm{FN} \text { branch } \\
-3^{\circ} \mathrm{FN} \text { branch depth from the cortical surface of the } \\
\text { mastoid triangle (junction of the triangle's mediana) } \\
-3^{\circ} \mathrm{FN} \text { branch } v s \text { lsc (nearest distance) } \\
-3^{\circ} \mathrm{FN} \text { branch } v s \text { psc (nearest distance) } \\
-3^{\circ} \mathrm{FN} \text { branch } v s \text { ssc (nearest distance) } \\
-3^{\circ} \mathrm{FN} \text { branch } v s \mathrm{SS} \text { (nearest distance) }\end{array}$ & $\begin{array}{l}17,8 \mathrm{~mm} \\
<1 \mathrm{~mm} \\
3,6 \mathrm{~mm} \\
5,6 \mathrm{~mm} \\
7,3 \mathrm{~mm}\end{array}$ & $\begin{array}{l}1,6 \mathrm{~mm} \\
- \\
1,8 \mathrm{~mm} \\
1,6 \mathrm{~mm} \\
2,4 \mathrm{~mm}\end{array}$ & $\begin{array}{l}15-20 \mathrm{~mm} \\
- \\
2-6 \mathrm{~mm} \\
4-7,5 \mathrm{~mm} \\
3-11 \mathrm{~mm}\end{array}$ \\
\hline $\begin{array}{l}\text { 5) SS } \\
\text { - SS (tip of the curvature) vs psc (tip of the curvature) } \\
\text { - SS (tip of the curvature) vs lsc (tip of the curvature) }\end{array}$ & $\begin{array}{l}7,8 \mathrm{~mm} \\
10,6 \mathrm{~mm}\end{array}$ & $\begin{array}{l}0,9 \mathrm{~mm} \\
1,5 \mathrm{~mm}\end{array}$ & $\begin{array}{l}6,5-9 \mathrm{~mm} \\
8,5-12,5 \mathrm{~mm}\end{array}$ \\
\hline
\end{tabular}


Table 2

Quantitative analysis in RS, RISTA, PLPA and ETCA

Table 2A: V c.n., clival length and brainstem area that are exposed through each approach

\begin{tabular}{|c|c|c|c|c|}
\hline $\begin{array}{l}\text { ANATOMIC LANDMARKS } \\
\text { EXPOSED }\end{array}$ & $\mathrm{RS}$ & RISTA & PLPA & ETCA \\
\hline $\begin{array}{l}\text { Length of the exposed V c.n. } \\
\text { from its pontine origin }(\mathrm{mm})\end{array}$ & $\begin{array}{l}\text { M: } 8 \\
\text { SD: } 0.8 \\
\text { R: } 7.6-8.4 \\
\end{array}$ & $\begin{array}{l}\text { M: } 12 \\
\text { SD: } 2.3 \\
\text { R: } 10.9-15\end{array}$ & $\begin{array}{l}\text { M: } 13.5 \\
\text { SD: } 1.7 \\
\text { R: } 12.9-14 \\
\end{array}$ & $\begin{array}{l}\text { M: } 15 \\
\text { SD: } 1.2 \\
\text { R: } 14-15.9 \\
\end{array}$ \\
\hline Exposed clival length (mm) & $\begin{array}{l}\text { M: } 16.5 \\
\text { SD: } 3.8 \\
\text { R: } 13.9-17.8 \\
\end{array}$ & $\begin{array}{l}\text { M: } 24.8 \\
\text { SD: } 3.7 \\
\text { R: } 22-26.8\end{array}$ & $\begin{array}{l}\text { M: } 28.5 \\
\text { SD: } 3.4 \\
\text { R: } 27.1-30.4 \\
\end{array}$ & $\begin{array}{l}\text { M: } 30 \\
\text { SD: } 3 \\
\text { R: } 28-33.4\end{array}$ \\
\hline $\begin{array}{l}\text { Length of the exposed clival } \\
\text { zone }(\mathrm{mm}) \\
\text { Zone I }(\%) \\
\text { Zone II }(\%) \\
\text { Zone III }(\%) \\
\end{array}$ & $\begin{array}{lll}\text { M: } 31.5 & \text { SD: } 3.1 & \text { R: } 25-35.5 \\
\text { M: } 88 & \text { SD: } 3 & \text { R: } 81-90 \\
\text { M: } 0 & \text { SD: / } & \text { R: / } \\
\end{array}$ & $\begin{array}{ll}\text { M: } 90 \text { SD: } 3.5 \text { R: } 87-93.5 \\
\begin{array}{lll}\text { M: } 88 \text { SD: } 3 & \text { R: } 81-90 \\
\text { M: } 0 & \text { SD: / } & \text { R: / } \\
\end{array}\end{array}$ & 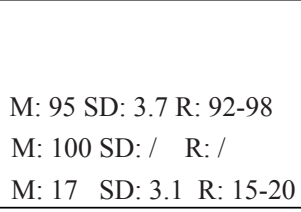 & $\begin{array}{l}\text { M: } 95 \text { SD: } 2.1 \text { R: } 93-98 \\
\text { M: } 100 \text { SD: / R: / } \\
\text { M: } 27 \text { SD: } 3.5 \text { R: } 22-35\end{array}$ \\
\hline $\begin{array}{l}\text { Area of the non-tangentially } \\
\text { exposed pontine surface } \\
\text { (infra }+/ \text { - supratentorial } \\
\text { point of view) }\left(\mathrm{mm}^{2}\right)\end{array}$ & $\begin{array}{l}\text { M: } 35 \\
\text { SD: } 4.7 \\
\text { R: } 27-40\end{array}$ & $\begin{array}{l}\text { M: } 55 \\
\text { SD: } 5 \\
\text { R: } 45-59\end{array}$ & $\begin{array}{l}\text { M: } 122 \\
\text { SD: } 8.2 \\
\text { R: } 117-140\end{array}$ & $\begin{array}{l}\text { M: } 170 \\
\text { SD: } 14.4 \\
\text { R: } 160-191\end{array}$ \\
\hline
\end{tabular}

Table 2B: key quantitative measurements for each approach

\begin{tabular}{|c|c|c|c|}
\hline APPROACHES AND MEASUREMENTS & MEAN & SD & RANGE \\
\hline $\begin{array}{l}\text { 1. RS } \\
\text { - petroclival angle (petrous ridge vs clival edge) }\end{array}$ & $45,5^{\circ}$ & $3,2^{\circ}$ & $42-47,8^{\circ}$ \\
\hline $\begin{array}{l}\text { 2. RISTA } \\
\text { - opening angle towards the superior clivus after } \\
\text { intradural apicectomy (posterior surface of the } \\
\text { drilled petrous apex vs petrous ridge) } \\
\text {-distance between the common crus and the } \\
\text { posterior petrous surface } \\
\text { - area enclosed among the posterior petrous } \\
\text { surface, brainstem, V c.n. and stato-acoustic bundle } \\
\text { - area enclosed among the posterior surface of } \\
\text { the drilled petrous apex, brainstem, V c.n. and } \\
\text { stato-acoustic bundle }\end{array}$ & $\begin{array}{l}3,4 \mathrm{~mm} \\
42 \mathrm{~mm}^{2} \\
84 \mathrm{~mm}^{2}\end{array}$ & $\begin{array}{l}1,3 \mathrm{~mm} \\
3,5 \mathrm{~mm}^{2} \\
1,9 \mathrm{~mm}^{2}\end{array}$ & $\begin{array}{l}8,6-9,3^{\circ} \\
2-5 \mathrm{~mm} \\
37-48 \mathrm{~mm}^{2} \\
81-88 \mathrm{~mm}^{2}\end{array}$ \\
\hline $\begin{array}{l}\text { 3. PLPA } \\
\text { - angle between the dissector along the posterior } \\
\text { petrous surface after PLPA vs clival border } \\
\text { - depth of the surgical corridor (from the ssc to } \\
\text { the brainstem) }\end{array}$ & $\begin{array}{r}90^{\circ} \\
26 \mathrm{~mm}\end{array}$ & $\begin{array}{l}1,3^{\circ} \\
3,1 \mathrm{~mm}\end{array}$ & $\begin{array}{l}85-92^{\circ} \\
23-30 \mathrm{~mm}\end{array}$ \\
\hline $\begin{array}{l}\text { 4. ETCA } \\
\text { - angle between the dissector along the } \\
\text { posterior petrous surface after ETCA and the } \\
\text { clival border }\end{array}$ & $97^{\circ}$ & $3,9^{\circ}$ & $93-105^{\circ}$ \\
\hline
\end{tabular}

Legend for tables: c.n.: cranial nerve; FN: Facial Nerve, JB: Jugular Bulb; p.c.f: posterior cranial fossa; SD: Standard Deviation; SDA: SinoDural Angle; SS: Sigmoid Sinus; lsc: lateral semicircular canal; psc: posterior semicircular canal; ssc: superior semicircular canal. 
c.n. and stato-acoustic bundle. Its mean value was $42 \mathrm{~mm}^{2}$ (it reaches a mean of $84 \mathrm{~mm}^{2}$ after intradural apicectomy) (Table 2B) and this indicates the ability the surgeon needs to drill inside such a restricted area bordered by major anatomic structures. The incidence toward the brainstem for each surgical approach (expressed in terms of pontine areas non-tangentially exposed) is from 35 and $55 \mathrm{~mm}^{2}$ for the retrosigmoid routes to 122 and $170 \mathrm{~mm}^{2}$ for the transpetrous approaches.

\section{Discussion}

Beginning with Hakuba et al. ${ }^{5}$ there have been various reports of hearing preservation after petrous surgery. Sekhar et al. ${ }^{17}$ describe $81 \%$ of hearing preservation in 36 patients operated on by PLPA with occlusion of the membranous labyrinth. The partial labyrinthine removal and the apicectomy in PLPA reduce the cerebral and JB dome (that is not often flat) retraction during clival and IAC exposure. This is because of the reduction of the petrous bone height and width which gives a larger working angle in the craniocaudal sense because of the absence of the ssc, and in a postero-anterior direction because of the removal of the psc.

The labyrinthine area drilled away during PLPA is triangular and despite its low mean surface area of $24.5 \mathrm{~mm}^{2}$ it significantly increases petroclival exposure. The posterior portion of the labyrinth obscures the antero-lateral pontine surface during the transpetrous approaches not associated with aperture of the otic capsule. Correct removal of this labyrinthine portion is easier in large mastoids and if the posterior fossa dura exposed through the mastoid cavity, the so-called Trautmann's triangle, is not too small and the structures at its vertices not too close to each other.

The relationships between the critical landmarks and the technical notes made during morphometric analysis help the surgeon, especially in cases with restricted working areas during the PLPA bony phase, making the whole procedure safer.

The quantitative measurements taken in our laboratory, with the limits implicit in the difficulty of CSF removal and the tissue texture caused the formaldehyde conservation technique (to get round this problem we simulate the brain retraction using prefixed cerebral sections), enabled us to evaluate the degree of surgical control of the V c.n. and the exposure of the clival length and area of brainstem through each approach.

The greater control of the V c.n. during PLPA offers better visualization of both Meckel's cave and the more medial structures such as the VI c.n. through Dorello's canal and the basilar artery.

The PLPA involves a surgical corridor that is perpendicular to the clival border and begins narrowing at the level where the $s s c$ and psc were removed. It is less deep than in retrosigmoid surgical approaches and reaches the brainstem in a 26- mm funnel-tract (Table 2B). The ssc was used as a landmark for the deep measurements and to evaluate the crossing point of the IV c.n. with the tentorial edge because the surgical route narrows from this semicircular canal onwards. The mean clival length exposed after PLPA was $28.5 \mathrm{~mm}$. The mean was similar $-30 \mathrm{~mm}$ - with the ETCA, reflecting the percentage of exposure of the Zone I-II-III (Table 2 A).

A quantitative estimate of the degree of clival exposure is mandatory during preoperative planning when we have to choose among invasive approaches with intrinsic postoperative morbidity such as the ETCA. On the other hand, the decision must also take account of the surgeon's experience with each single surgical route, the so-called "parameters linked to the patient"15 and the adjuvant therapies (radiosurgery or other). If the surgeon is not familiar with the transpetrous approaches there is a high probability of damaging key structures such as the membranous labyrinth during PLPA.

The hearing loss problem should be avoided or reduced by choosing the retrosigmoid routes. However, during the RISTA two main factors increase the difficulty of execution: the first is the intradural apicectomy which is done with the cranial nerves interposed between the surgeon and the petrous apex that is to be drilled away. The second is the depth of the surgical corridor (mostly when we work at the level of Zones II and I), the difficulty of controlling bleeding from the $\mathrm{SpS}$ and, finally, the care the surgeon must take to avoid the common crus that is only $3.4 \mathrm{~mm}$ deep from the posterior petrous surface (Table $2 \mathrm{~B}$ ). However, the RISTA, with or without a temporal craniotomy, is recommended to remove large petroclival meningiomas without hearing dysfunction ${ }^{12}$. The RISTA, even if it is a retrosigmoid route, gives a bigger working angle towards the upper clivus, enlarging the passage from $16.5 \mathrm{~mm}$ (value obtained during the RS) to $24.8 \mathrm{~mm}$ of clival exposure.

Evaluation of the V c.n. and clival exposures for each surgical route is the first step in pre-operative planning. The second phase is quantitative analysis of the brain tissue exposure in the petroclival area and the brainstem surface that might be indented by the meningioma. Surgical control of the antero-lateral surface of the brainstem is tightly linked to the maximal incidence angle with the clival border during each approach. The PLPA is the surgical route that, after the ETCA, gives the largest angle (mean 90, $\mathrm{SD}$ $1.3^{\circ}$ ). It allows an antero-posterior excursion on the ventral pontine surface. This kind of surgical control also depends on the degree of excursion in a cranio-caudal sense during approaches combined with a temporal craniotomy and of course it is directly proportional to the reduction in height 
of the petrous bone. The ETCA produces the maximal excursion, just ahead of the PLPA, among the approaches considered here.

We measured the pontine surface exposed from an infratentorial +/- supratentorial viewpoint for each approach. A non-tangential $122 \mathrm{~mm}^{2}$ exposure of the ventral pontine aspect (controlling in particular the upper 50\%) was possible during PLPA thanks to the reduction in the height of the petrous bone. This is linked to the supratentorial viewpoint. The lower mid-portion control, especially on the antero-lateral surface, is ensured by the pre-sigmoid entry of the surgical corridor. Fuller non-tangential control is obtained by removing the residual petrous bone and transposing the VII c.n. as during the ETCA, that offers $170 \mathrm{~mm}^{2}$ exposure of the pontine surface. The RISTA does not increase the non-tangential pontine exposure, because it offers a surgical opening of $9^{\circ}$ towards the upper clivus and not towards the brainstem.

Our anatomic data suggest that the surgical routes that preserve the petrous apex and the labyrinth reduce the brainstem surface controlled in a non-tangential manner. This implies that the transcrusal approach could be used when the tumor causes a pontine indentation (especially of the upper mid-portion), with an extension towards the middle and upper central clivus. If necessary, it can be converted to a wider approach such as the ETCA one ${ }^{4}$.

Finally, considering the ETCA, our data and other studies $^{8,9,14}$ suggest that it is indicated, for example, for giant meningiomas centrally located at the middle and upper clivus that cause a global pontine indentation, and possibly also dislocate it controlaterally with encasement of the vertebro-basilar complex. Hearing function controlaterally to the petrosectomy should be preserved.

On the other hand, the RS is recommended if the meningioma extends itself more laterally toward the cerebellopontine cistern ${ }^{4,18}$. This is confirmed by our findings, depending on the osteo-dural and cerebral exposures. Major extension of the tumor toward Meckel's cave should induce the surgeon to choose the RISTA.

Our analysis could be useful for the surgeon during pre-operative planning considering that the operative risks may be reduced if a residual tumor is left in place in some situations. Radiosurgery is a useful adjuvant therapy in these cases ${ }^{1,2}$.

In the future CT and MRI units targeted for interactive virtual image-guided surgery and not solely for diagnostic purposes should be used during the pre-operative phase. The surgeon's familiarity with the temporal bone anatomy acquired during laboratory dissections is fundamental before petrous surgery and cannot be replaced by imageguided systems even if they are based on the navigator technique.

In conclusion the PLPA is included among the skull- base transpetrous procedures. It offers the advantages of extended exposure of the petroclival region, with limited postoperative morbidity. It offers a non-tangential $122 \mathrm{~mm}^{2}$ exposure of the ventral pontine aspect (controlling in particular the upper 50\%) thanks to the reduction in the height of the petrous bone that helps markedly increase the angle of incidence toward the brainstem in comparison to the retrosigmoid routes. The RISTA is particularly indicated for tumors growing toward Meckel's cave. More invasive approaches, such as the ETCA, should be limited to certain specific tumors and cases where the combination of less invasive surgical procedures with radiosurgery is not advisable.

Thorough knowledge of the morphometric anatomy of the temporal bone is mandatory for the surgeon undertaking transpetrous approaches. The help supplied by modern technologies and collaboration between neurosurgeons and neuroradiologists are of primary importance for pre-surgical decision-making in this kind of surgery.

\section{Acknowledgements}

The authors thank Professor J. Usón, Scientific Director of the Minimally Invasive Surgery Centre (Cáceres, Spain) for helpful discussions.

This work was supported in part by grant no. SCSS0633 from the Junta de Extremadura.

\section{References}

1. Abdel Aziz, K.M., Sanan, A., van Loveren, H.R., Tew, J.M. Jr, Keller, J.T., Pensak, M.: Petroclival meningiomas: predictive parameters for transpetrosal approaches. Neurosurgery 2000; 47: 139-152.

2. Aichholzer, M., Bertalanffy, A., Dietrich, W., Roessler, K., Ungersboeck, K., Heimberger, K., Kitz, K.: Gamma knife radiosurgery of skull base meningiomas. Acta Neurochir (Wien) 2000; 142: 647-653.

3. Aslan, A., Falcioni, M., Russo, A., De Donato, G., Balyan, F.R., Taibah, A., Sanna, M.: Anatomical considerations of high jugular bulb in lateral skull base surgery. J Laryngol Otol 1997; 111: 333-336.

4. Chanda, A., Nanda, A.: Partial Labyrinthectomy Petrous Apicectomy Approach to the petroclival region: an anatomic and technical study. Neurosurgery 2002; 51: 147-160.

5. Hakuba, A., Nishimura, S., Jang, B.J.: A combined retroauricular and preauricular transpetrosal-transtentorial approach to clivus meningiomas. Surg Neurol 1988; 30: 108116.

6. Horgan, M.A., Anderson, G.J., Kellogg, J.X., Scwartz, M.S., Spektor, S., McMonomey, S.O., Delashaw, J.B.: Classification and quantification of the petrosal approach to the petroclival region. J Neurosurg 2000; 93: 108-112. 
7. McElveen, J.T., Wilkins, R.H., Molter, D.W., Erwin, A.C., Wolford, R.D..: Hearing preservation using the modified translabyrinthine approach. Otolaryngol Head Neck Surg 1993: 108: 671-679.

8. Miller, G.C., van Loveren, H.R., Keller, J.T., Pensak, M., El-Kalliny, M., Tew, J.M.: Transpetrosal approach: Surgical anatomy and Technique. Neurosurgery 1993; 33: 461469.

9. Mortini, P., Mandelli, C., Franzin, A., Giugni, E., Giovanelli, M.: Surgical excision of clival tumors via the enlarged transcochlear approach: indications and results. J Neurosurg Sci 2001; 45: 127-140.

10. Rhoton, A.L.: The temporal bone and transtemporal approaches. Neurosurgery 2000; 47(S3): 211-265.

11. Rosenwasser, R.H, Buchheit, W.A.: Acoustic Neuromas - Suboccipital Approach. En: Apuzzo, M.L.J. (ed). Brain Surgery: Complication avoidance and management. New York; Churchill Livingstone Inc, 1993; Vol 2, pp. 1743-1800.

12. Samii, M., Tatagiba, M., Carvalho, G.A.: Resection of large petroclival meningiomas by the simple retrosigmoid approach. J Clin Neurosci 1999; 6: 27-30.

13. Sanan, A., Abdel Aziz, K.M., Janjua, R.M., van Loveren, H.R., Keller, J.T.: Colored silicone injection for use in neurosurgical dissections: anatomic technical note. Neurosurgery 1999; 45: 1267-1274.

14. Sanna, M., Saleh, E., Russo, A., Taibah, A.: The Transcochlear Approaches. En: Sanna, M., Saleh, E., Russo, A., Taibah, A. (eds.). Atlas of temporal bone and lateral skull base surgery. New York; Thieme Medical Publishers, 1995; pp.51-87.

15. Sekhar, L.N., Jannetta, P.J., Burkhart, L.E., Janosky,
J.E.: Meningiomas involving the clivus: a six-year experience with 41 patients. Neurosurgery 1990; 27: 764-781.

16. Sekhar, L.N., Raso, J.L., Schessel, D.A.: The presigmoid petrosal approach. En: Sekhar, L.N., De Oliveira, E. (eds.). Cranial Microsurgery - Approaches and Techniques. New York; Thieme Medical Publishers Inc, 1999; pp.432463.

17. Sekhar, L.N., Schessel, D.A., Bucur, S., Raso, J.L., Wright, D.C.: Partial Labyrinthectomy Petrous Apicectomy Approach to neoplastic and vascular lesions of the petroclival area. Neurosurgery 1999; 44: 537-552.

18. Sekhar, L.N., Tzortzdis, F.: Retrosigmoid approach to the cerebellopontine angle. En: Sekhar, L.N., De Oliveira, E. (eds.). Cranial Microsurgery - Approaches and Techniques. New York; Thieme Medical Publishers Inc, 1999; pp.352377.

19. Seoane, E., Rhoton, A.L.: Suprameatal extension of the retrosigmoid approach: microsurgical anatomy. Neurosurgery 1999; 44: 553-560.

Mandelli, C.; Porras, L.; López-Sánchez, C.; Sicuri, G.M.; Lomonaco, I.; García-Martínez, V.: The partial labyrinthectomy petrous apicectomy approach to petroclival meningiomas. A quantitative anatomic comparison with other approaches to the same region. Neurocirugía 2008; 19: 133-142.

Correspondig author: Carlo Mandelli, MD. Department of Neurosurgery, IRCCS San Raffaele. Università Vita-Salute. Milano. Italy. 